\title{
Rapid determination of histamine concentration in fish (Miichthys Miiuy) by surface-enhanced Raman spectroscopy and density functional theory
}

\author{
Chu Bingquan, Lin Lei, He Yong* \\ (College of Biosystems Engineering and Food Science, Zhejiang University, Hangzhou Zhejiang 310058, China)
}

\begin{abstract}
Histamine is a type of biogenic amine, which plays a major role in the health problems associated with seafood consumption. Legislative limits of histamine level in seafood have been set in many countries. This study focuses on investigating the feasibility and potentiality of determining histamine concentration in fish (Miichthys miiuy) by surface-enhanced Raman spectroscopy (SERS) combined with density functional theory (DFT). Both a gold colloid and a silver colloid were used to determine the enhancement effect for SERS detection of histamine standard solution, and the gold colloid exhibited more effective as compared to the silver colloid. The protocol on extraction of histamine with $12 \%$ trichloroacetic acid and adjustment of $\mathrm{pH}$ with $\mathrm{NaOH}$ solution $(5 \mathrm{~mol} / \mathrm{L})$ could significantly shorten sample preparation $(20 \mathrm{~min})$ and provide clear SERS spectra of histamine. The peaks of histamine molecules were classified using the DFT and five spectra $\left(953 \mathrm{~cm}^{-1}, 992 \mathrm{~cm}^{-1}, 1106 \mathrm{~cm}^{-1}, 1262 \mathrm{~cm}^{-1}\right.$ and $\left.1317 \mathrm{~cm}^{-1}\right)$ were selected as the characteristic bands of histamine discrimination. Moreover, the intensity of the peak at $1262 \mathrm{~cm}^{-1}$ had a good linear relationship with histamine concentration at $5-400 \mathrm{mg} / \mathrm{kg}$ with $R^{2}=0.9755$. It is concluded that the SERS-DFT approach will be a potential method for rapidly and reliably detecting histamine at levels from $5 \mathrm{mg} / \mathrm{kg}$ to $400 \mathrm{mg} / \mathrm{kg}$ in fresh fish.
\end{abstract}

Keywords: surface-enhanced Raman spectroscopy (SERS), density functional theory (DFT), gold nanoparticles, histamine, rapid determination, fish (Miichthys miiuy), food safety

DOI: $10.25165 /$ j.ijabe.20171004.3468

Citation: Chu B Q, Lin L, He Y. Rapid determination of histamine concentration in fish (Miichthys Miiuy) by surface-enhanced Raman spectroscopy and density functional theory. Int J Agric \& Biol Eng, 2017; 10(4): 252-258.

\section{Introduction}

Biogenic amine (BA) is a general name for non-volatile aliphatic, alicyclic or heterocyclic nitrogen-containing organic compounds. BA has some biological activities, which is widely found in organisms and a variety of food ${ }^{[1]}$. The proper amount of BA in the

Received date: 2017-05-04 Accepted date: 2017-06-15

Biographies: Chu Bingquan, $\mathrm{PhD}$ candidate, research interest: nondestructive testing techniques for food and agricultural products, Email: chubingquan10@163.com; Lin Lei, PhD candidate, research interest: optics-electrics application of biomaterials technology, Email: 115127195@qq.com.

*Corresponding author: He Yong, PhD, Professor, research interests: intelligent agricultural technology, precision agriculture. College of Biosystems Engineering and Food Science, Zhejiang University, 866 Yuhangtang Road, Hangzhou 310058, Zhejiang, China. Tel/Fax: +86-571-88982143; Email: yhe@zju.edu.cn. body has vital physiological activities, such as regulating the secretion of neurotransmitters, controlling blood pressure, and participating in immune response $\mathrm{e}^{[2-4]}$. However, when its intake is too high or there is too much accumulation in the body, it may be toxic to human health. Among BA, histamine is the most toxic one. Studies have shown that it can lead to mild poisoning when the intake of histamine content reaches $8-40 \mathrm{mg}$, and the histamine concentration of more than $100 \mathrm{mg}$ may cause vomiting, dizziness, diarrhea, allergies and other serious poisoning reactions, and even lead to shock or death ${ }^{[3]}$. The National Food Safety Standards of China has directed that the average of histamine content in fresh fish is set at $400 \mathrm{mg} / \mathrm{kg}$ for high histamine-contained fish (such as mackerel, tuna, et al.) and $200 \mathrm{mg} / \mathrm{kg}$ for other fish for food safety ${ }^{[5]}$; while the European Union (EU) limit is more strict and set at 
$100 \mathrm{mg} / \mathrm{kg}^{[6]}$. In addition, the Food and Drug Administration (FDA) sets histamine content of more than $50 \mathrm{mg} / \mathrm{kg}$ as a standard to assess the deterioration of fish $^{[7]}$. Therefore, a reliable and rapid detection method of histamine in fish is of great significance to ensure the quality of fish and the health of consumers.

Traditional methods for the detection of histamine in fish are mainly by high-performance liquid chromatography (HPLC), fluorescence quantification, ion exchange chromatography, capillary electrophoresis and enzymelinked immunosorbent assay ${ }^{[8-11]}$. Although the sensitivities of these methods are high, the cumbersome pre-test, time-consuming detection, inconvenient instrument, expensive reagents and other shortcomings limit their applications, e.g. the pre-processing time for the histamine determination in fish takes up to $5 \mathrm{~h}$ according to the Chinese national standard method ${ }^{[5]}$. Surface-enhanced Raman spectroscopy (SERS) is a highly sensitive fingerprint. The "surface-enhanced" describes the characteristic that the Raman signal of a compound molecule can be enhanced in geometric multiple when it adsorbs on some nanoscale rough metals surface (such as gold, silver and copper) or in the sol ${ }^{[12-14]}$. Thus, the SERS technology can achieve rapid detection of trace samples and single molecules. At the same time, SERS has the advantages of simple pretreatment method, convenient equipment and fast detection speed, and is widely used in the rapid screening of pesticide residues in agricultural products, the detection of trace substances in food, and the detection of harmful substances in the environment ${ }^{[15-17]}$. Gao et al. ${ }^{[18]}$ successfully established a method for rapid detection of histamine content in canned tuna by molecularly imprinted polymers combined with the SERS technique, which used gold nanoparticles as a substrate. The detection range was 3-90 ppm. Xie et al. ${ }^{[19]}$ established a method for rapid screening of histamine in fish by SERS combined with a thin-layer chromatography method. The accuracy and sensitivity of the method were comparable to those used by the EU. Zhang et al. ${ }^{[20]}$ used the SERS technique to analyze the content of calcium dipicolinate (CaDPA), a biomarker of Bacillus anthracis. The results showed that data collection could rapidly analyze CaDPA corresponding to the amount of $10^{4}$ spores with only $5 \mathrm{~s}$ spent based on silver nanoparticle, which showed a good prospect for SERS in environmental hazard detection. Nevertheless, few studies have been comprehensively conducted on detecting the histamine content in fresh fish using SERS. In this study, a simple sample preparation protocol and SERS combined with DFT were used to test the applicability of the approach for rapid determination of histamine in the muscle of fresh fish.

\section{Materials and methods}

\subsection{Materials}

Histamine (purity $>97.0 \%$ ) was obtained from Sigma-Aldrich (St Louis, MO, USA); trichloroacetic acid and sodium hydroxide were purchased from Sinopharm Chemical Reagent Co., Ltd (Shanghai, China); silver nitrate, chloroauric acid, sodium citrate and sodium chloride were obtained from Jingchun Industrial Co., Ltd (Shanghai, China). All the reagents are analytical pure.

Fresh fishes (Miichthys miiuy) were provided by Fenghua Xingyang Aquatic Food Co., Ltd., which were collected from Ningbo Fenghua seafood fishing base and shipped to the laboratory (Hangzhou, China) at $-20^{\circ} \mathrm{C}$ within $12 \mathrm{~h}$. The experimental water is double deionized water (ultra-pure water).

\subsection{Instrumentation}

RamTracer-200-HS portable Raman spectrometer equipped with a $785 \mathrm{~nm}$ excitation wavelength of a diode frequency stabilizer (OptoTrace Technologies, USA); a ZNCL intelligent thermostat magnetic stirrer (Zhengzhou Yalong, China); a Vortex-Genie $2 / 2 \mathrm{~T}$ vortex mixer (Shanghai Lingling, China); An FEI Tecnai G2 F20 S-TWIN transmission electron microscope (FEI, USA); a BSA124S-CW electronic balance with the accuracy of $0.1 \mathrm{mg}$ (Sartotius, Germany); a JW-1024 low-speed centrifuge with the maximum speed of $4500 \mathrm{r} / \mathrm{min}$ (Anhui Jiawen, China).

\subsection{Sample preparation}

The back muscles of Miichthys miiuy were chopped and minced by a meat grinder. Seventeen samples were accurately weighed ( $5 \mathrm{~g}$ each) and spiked with $0.1 \mathrm{~mL}$ of different concentrations of histamine standard solution (with $12 \%$ trichloroacetic acid) to obtain the final 
concentrations of $5 \mathrm{mg} / \mathrm{kg}, 25 \mathrm{mg} / \mathrm{kg}, 50 \mathrm{mg} / \mathrm{kg}, 75 \mathrm{mg} / \mathrm{kg}$, $100 \mathrm{mg} / \mathrm{kg}, 125 \mathrm{mg} / \mathrm{kg}, 150 \mathrm{mg} / \mathrm{kg}, 175 \mathrm{mg} / \mathrm{kg}, 200 \mathrm{mg} / \mathrm{kg}$, $225 \mathrm{mg} / \mathrm{kg}, 250 \mathrm{mg} / \mathrm{kg}, 275 \mathrm{mg} / \mathrm{kg}, 300 \mathrm{mg} / \mathrm{kg}, 325 \mathrm{mg} / \mathrm{kg}$, $350 \mathrm{mg} / \mathrm{kg}, 375 \mathrm{mg} / \mathrm{kg}, 400 \mathrm{mg} / \mathrm{kg}$. Meanwhile, the fresh muscle spiked without histamine was set as a blank sample, which was confirmed to be histamine free according to the method described in Chinese national standard method (GB/T 5009. 208-2008) ${ }^{[21]}$.

The histamine standard working solution at a concentration of $10.0 \mathrm{mg} / \mathrm{L}$ was prepared with $12 \%$ trichloroacetic acid.

\subsection{Sample treatment}

The spiked samples (5 g) were mixed with trichloroacetic acid $(12 \%)$ at a $1: 10$ solid-liquid ratio ${ }^{[22]}$. They were continuously mixed during ultrasonic extraction which was at $60 \mathrm{~W}$ for $5 \mathrm{~min}$ at $50^{\circ} \mathrm{C}$. The samples were spun in a centrifuge at $3600 \mathrm{r} / \mathrm{min}$ for $5 \mathrm{~min}$. The supernatant was filtered through two layers of quantitative filter paper to obtain the extract and then filled with trichloroacetic acid $(12 \%)$ to $50 \mathrm{~mL}$. Ten milliliter of the extract was taken and put in a $25 \mathrm{~mL}$ glass tube with plug, $2.5 \mathrm{~mL}$ of $5 \mathrm{~mol} / \mathrm{L} \mathrm{NaOH}$ solution was added and vortex mixing, so as to adjust $\mathrm{pH}$ over 12 . And $100 \mu \mathrm{L}$ of the mixture was taken for the SERS machine detection. Total time of sample preparation was approximately $20 \mathrm{~min}$.

After the same pretreatment (adjust $\mathrm{pH}$ ), two portions $(10 \mathrm{~mL}$ each) of $10.0 \mathrm{mg} / \mathrm{L}$ histamine standard working solution were used to determine nanoparticles (gold or silver) for histamine SERS.

\subsection{Preparation of silver and gold nanoparticles}

The trisodium citrate heating reduction method was slightly modified according to the literature for the preparation of gold nanoparticle ${ }^{[23]}$. The process was as follows. A chloroauric acid solution $(50 \mathrm{mg} / \mathrm{L})$ was poured in a flask, which was heated to boiling at $120^{\circ} \mathrm{C}$ on a constant temperature magnetic stirrer. Then $4 \mathrm{~mL}$ of trisodium citrate solution $(5 \mathrm{mg} / \mathrm{mL})$ was added. The mixture was stirred at the speed of $100 \mathrm{r} / \mathrm{min}$ to prepare gold sol into the color of the wine red. After the solution was cooled, the above gold gel solution was poured into a centrifuge tube. The supernatant $(2 \mathrm{~mL})$ was removed after centrifugation. And then $1 \mathrm{~mL}$ ultra-pure water was added to the centrifuge tube and mixed with ultrasonic oscillation. After repeating purification, the gold colloid was stored in dark.

The preparation of silver nanoparticle was established on the basis of the Lee-Meisel trisodium citrate heating reduction $\operatorname{method}^{[24]}$. A silver nitrate solution $(180 \mathrm{mg} / \mathrm{L})$ was poured into the flask, which was heated quickly to boiling at the high temperature on a constant temperature magnetic stirrer. A $1 \%$ trisodium citrate solution $(60 \mathrm{mg}$ of trisodium citrate dissolved in $6 \mathrm{~mL}$ of ultra-pure water) was gradually added dropwise over $2 \mathrm{~min}$ while stirring at $200 \mathrm{r} / \mathrm{min}$. Then it was stored in dark after the solution turned to gray-green in $25 \mathrm{~min}$.

\subsection{Raman spectroscopy acquisition}

The acetonitrile was utilized for instrument calibration with an excitation wavelength of $785 \mathrm{~nm}$ before Raman spectra were collected. Herein, the power, the scanning range, the optical resolution and the integration time were set as $200 \mathrm{~mW}, 200-3300 \mathrm{~cm}^{-1}$, $2 \mathrm{~cm}^{-1}$, and $10 \mathrm{~s}$, respectively. The average spectral value was collected three times. The histamine powder was planished with a glass slide on the quartz plate, which was collected with a matching microscope platform.

SERS acquisition: $500 \mu \mathrm{L}$ of the nano-enhancer, $100 \mu \mathrm{L}$ of samples and $100 \mu \mathrm{L}$ of sodium chloride (1\%) were added in turn into a quartz vial, which was used for SERS spectral acquisition after mixed.

\subsection{Data analysis and processing}

All computations and data analyses were performed with the aid of MATAB R2014a, Gaussian.v09, OMNIC v8.2, Origin v8.0, and SPSS V17.0.

\section{Results and discussion}

\subsection{Raman spectroscopy analysis of histamine}

The theoretical Raman spectroscopy of histamine (molecular formula $\mathrm{C}_{5} \mathrm{H}_{9} \mathrm{~N}_{3}$ ) was calculated by using the B3LYP hybrid function of DFT. Meanwhile, B3LYP was the Becke3 parameter density functional model. The molecular structure is shown in Figure 1, which is mainly composed of imidazole ring, $\mathrm{C}-\mathrm{N}, \mathrm{C}=\mathrm{N}, \mathrm{C}=\mathrm{C}$, $\mathrm{C}-\mathrm{C}, \mathrm{C}-\mathrm{H}, \mathrm{N}-\mathrm{H}$ and other groups. The Raman spectra peaks of histamine can be resolved according to the 
characteristic frequency of functional groups.

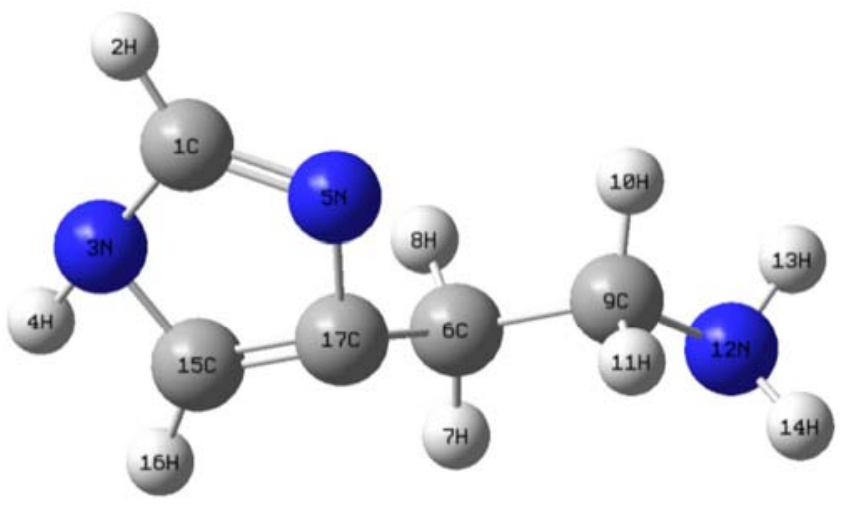

Figure 1 Schematic drawing of the structure of histamine

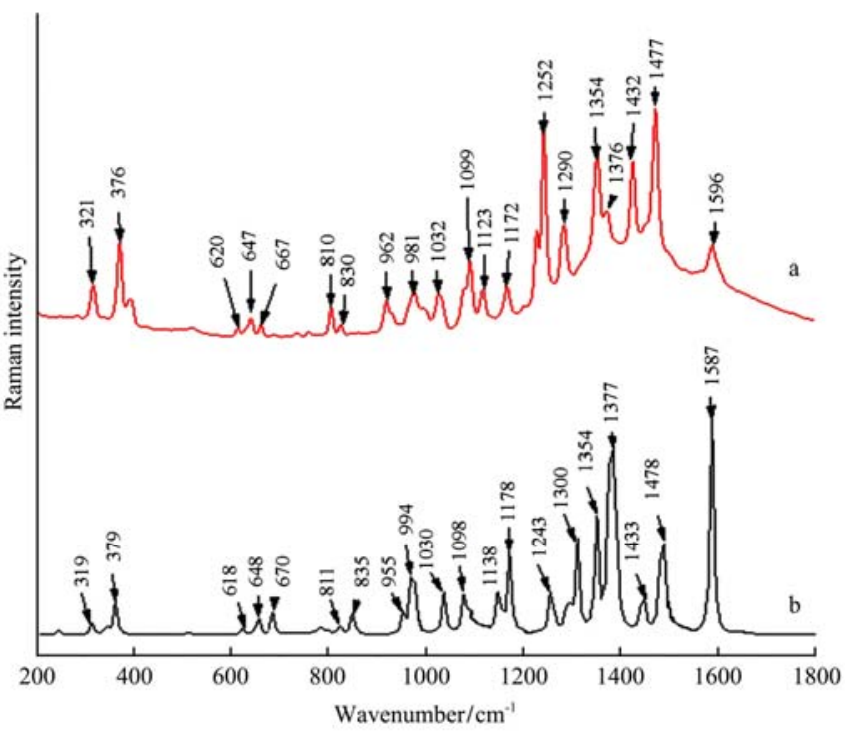

Figure 2 Raman spectra of histamine solid (a) and the theoretical calculation (b)

Raman peaks of histamine solid $\left(321 \mathrm{~cm}^{-1}, 376 \mathrm{~cm}^{-1}\right.$, $647 \mathrm{~cm}^{-1}, 810 \mathrm{~cm}^{-1}, 1032 \mathrm{~cm}^{-1}, 1099 \mathrm{~cm}^{-1}, 1376 \mathrm{~cm}^{-1}$, $1432 \mathrm{~cm}^{-1}$ and $1477 \mathrm{~cm}^{-1}$ ) (Figure 2a) were basically in line with those $\left(319 \mathrm{~cm}^{-1}, 379 \mathrm{~cm}^{-1}, 648 \mathrm{~cm}^{-1}, 811 \mathrm{~cm}^{-1}\right.$, $1030 \mathrm{~cm}^{-1}, 1098 \mathrm{~cm}^{-1}, 1377 \mathrm{~cm}^{-1}, 1433 \mathrm{~cm}^{-1}$ and $1478 \mathrm{~cm}^{-1}$ ) calculated by the DFT (Figure $2 \mathrm{~b}$ ). Table 1 presents the peaks of histamine reviewed by the references ${ }^{[19,25]}$. Among them, $321 \mathrm{~cm}^{-1}$ and $376 \mathrm{~cm}^{-1}$ were attributed to the outward bending vibration of the skeleton in the histamine molecules, and the peaks at $647 \mathrm{~cm}^{-1}$ and $810 \mathrm{~cm}^{-1}$ were the outer ring vibration of the histamine molecules. The peaks at $1032 \mathrm{~cm}^{-1}$ and $1099 \mathrm{~cm}^{-1}$ were due to the $\mathrm{C}-\mathrm{H}$ surface deformation vibration and the $\mathrm{C}-\mathrm{N}$ stretching vibration of the histamine molecules, respectively. Moreover, the peaks at $1376 \mathrm{~cm}^{-1}$ and $1477 \mathrm{~cm}^{-1}$ were the ring stretching vibration, and the peak at $1432 \mathrm{~cm}^{-1}$ was the ring vibration of the histamine molecules and the in-plane bending vibration of the N-H group. These peaks could serve as the Raman characteristic peaks of histamine.

Table 1 Proposed assignment of Raman bands of histamine

\begin{tabular}{|c|c|c|c|}
\hline Calculation ${ }^{\mathrm{a}} / \mathrm{cm}^{-1}$ & Solid ${ }^{\mathrm{b}} / \mathrm{cm}^{-1}$ & $\mathrm{SERS}^{\mathrm{b}} / \mathrm{cm}^{-1}$ & Assignment \\
\hline 319 & $321(\mathrm{~m})$ & $313(w)$ & $\delta$ Skeletal \\
\hline 379 & $373(\mathrm{~s})$ & $363(\mathrm{~m})$ & $\delta$ Skeletal \\
\hline 618 & $620(w)$ & - & $\gamma$ Ring \\
\hline 647 & $648(w)$ & $647(w)$ & $\gamma$ Ring \\
\hline 670 & $667(w)$ & $667(w)$ & $\gamma$ Ring \\
\hline 811 & $811(\mathrm{~m})$ & $811(w)$ & $\delta(\mathrm{C}-\mathrm{H})$ \\
\hline 835 & $830(w)$ & $838(w)$ & $\delta$ Ring \\
\hline 955 & $962(\mathrm{~m})$ & $953(w)$ & $\delta$ Ring, $\gamma(\mathrm{N}-\mathrm{H})$ \\
\hline 994 & $981(\mathrm{~m})$ & 992(w) & $\delta(\mathrm{C}-\mathrm{H})$ \\
\hline 1030 & 1032(m) & $1030(\mathrm{~m})$ & $\delta(\mathrm{C}-\mathrm{H})$ \\
\hline 1098 & 1099(s) & $1106(w)$ & $v(\mathrm{C}-\mathrm{N})$ \\
\hline 1138 & $1123(\mathrm{~m})$ & $1129(w)$ & $\mathrm{Y}(\mathrm{N}-\mathrm{C}-\mathrm{N}), \delta(\mathrm{N}-\mathrm{H})$ \\
\hline 1178 & $1172(\mathrm{~m})$ & $1186(w)$ & $\delta(\mathrm{N}-\mathrm{H})$ \\
\hline 1243 & $1252(\mathrm{vs})$ & $1262(\mathrm{~s})$ & $\delta(\mathrm{C}-\mathrm{H})$, Ring breathing \\
\hline 1252 & $1252(\mathrm{vs})$ & $1262(\mathrm{~s})$ & Ring breathing \\
\hline 1300 & $1290(\mathrm{~s})$ & $1317(\mathrm{~s})$ & $v$ Ring \\
\hline 1344 & 1354(vs) & - & $\delta$ Ring \\
\hline 1377 & $1376(w)$ & 1377(w) & $v$ Ring \\
\hline 1433 & $1432(\mathrm{~s})$ & $1425(w)$ & $\delta(\mathrm{N}-\mathrm{H}), v$ Ring \\
\hline 1478 & 1477(vs) & - & $v$ Ring \\
\hline 1587 & $1596(\mathrm{~m})$ & $1593(\mathrm{vs})$ & $v$ Ring, $v(C=C)$ \\
\hline
\end{tabular}

\subsection{Comparison of the enhancement effects of silver} or gold nanoparticle on histamine

The SERS spectra of the histamine standard solution $(10 \mathrm{mg} / \mathrm{mL})$ with silver and gold nanoparticle are shown in Figure 3 ( $a$ and $b$ ), where the Raman peaks at $953 \mathrm{~cm}^{-1}$, $992 \mathrm{~cm}^{-1}, 1030 \mathrm{~cm}^{-1}, 1106 \mathrm{~cm}^{-1}, 1186 \mathrm{~cm}^{-1}, 1262 \mathrm{~cm}^{-1}$, $1317 \mathrm{~cm}^{-1}, 1425 \mathrm{~cm}^{-1}$ and $1593 \mathrm{~cm}^{-1}$ were strong, and the wavenumbers of these characteristic peaks are shown in Table 1. However, there were only five weak peaks $\left(432 \mathrm{~cm}^{-1}, 749 \mathrm{~cm}^{-1}, 844 \mathrm{~cm}^{-1}, 939 \mathrm{~cm}^{-1}\right.$ and $\left.1339 \mathrm{~cm}^{-1}\right)$ in the Raman spectra of histamine untreated with surface enhancer (Figures $3 \mathrm{c}$ and $3 \mathrm{~d}$ ).

Structures of silver and gold nanoparticles were characterized by transmission electron microscopy (TEM). Results showed that the diameter of silver nanoparticles was about $60 \mathrm{~nm}$ and that of gold nanoparticles was $40 \mathrm{~nm}$. The sizes of the two nanoparticles were uniform. The enhancement effect of gold nanoparticles on histamine molecules was higher significantly at $953 \mathrm{~cm}^{-1}, 992 \mathrm{~cm}^{-1}, 1262 \mathrm{~cm}^{-1}, 1106 \mathrm{~cm}^{-1}$, 
$1262 \mathrm{~cm}^{-1}, 1317 \mathrm{~cm}^{-1}, 1425 \mathrm{~cm}^{-1}$ and $1593 \mathrm{~cm}^{-1}$ as use gold nanoparticles.

compared with silver colloid. Follow-up study would

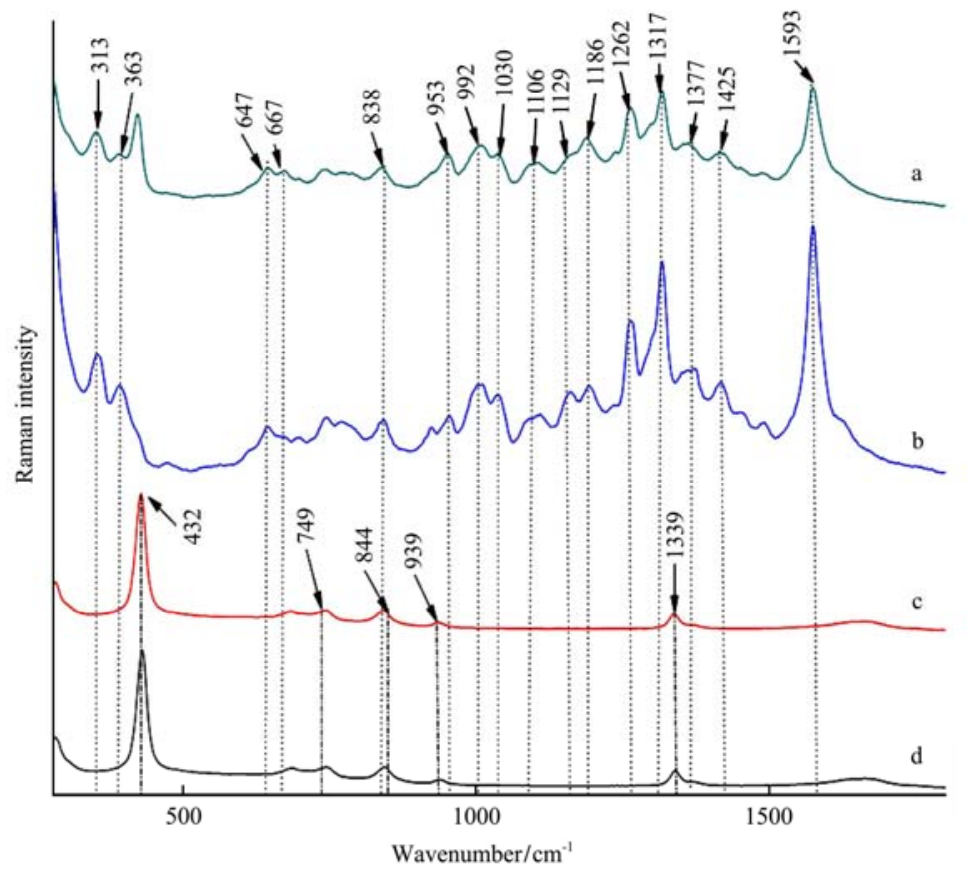

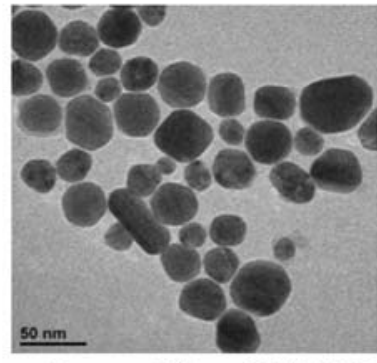

e. Structure of silver colloid (TEM)

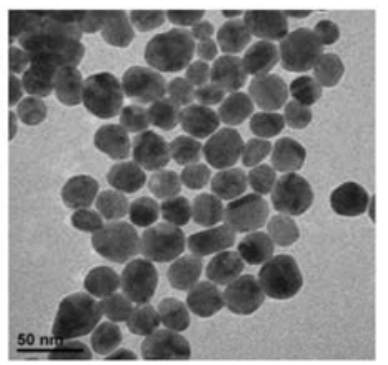

f. Structure of gold colloid (TEM)

Figure 3 Raman spectra of histamine treated with silver colloid (a) and its structure characterized by TEM (e) or gold colloid (b) and its structure characterized by TEM (f) or histamine untreated with surface enhancer (c) and blank (12\% trichloroacetic acid) (d)

3.3 Qualitative and quantitative analyses of SERS on histamine concentration in Miichthys Miiuy

SERS spectra of all samples were processed via smoothing and baseline correction in order to remove the effects of noise and baseline drift. As the extract was not degreased, the SERS results showed a large number of impure peak signals. However, except for the blank SERS spectra signal of Miichthys Miiuy in Figure 4 (q), five histamine Raman characteristic peaks $\left(953 \mathrm{~cm}^{-1}\right.$,
$992 \mathrm{~cm}^{-1}, 1106 \mathrm{~cm}^{-1}, 1262 \mathrm{~cm}^{-1}$ and $1317 \mathrm{~cm}^{-1}$ ) could be identified clearly, and the intensities of peaks gradually decreased as the concentration of histamine decreased. Additionally, when the concentration of histamine in spiked fish was $5 \mathrm{mg} / \mathrm{kg}$, the signal could still be effectively identified. Therefore, the five characteristic peaks were selected as the basis for qualitative and quantitative determination of histamine in Miichthys Miiuy at the concentration of $5-400 \mathrm{mg} / \mathrm{kg}$.

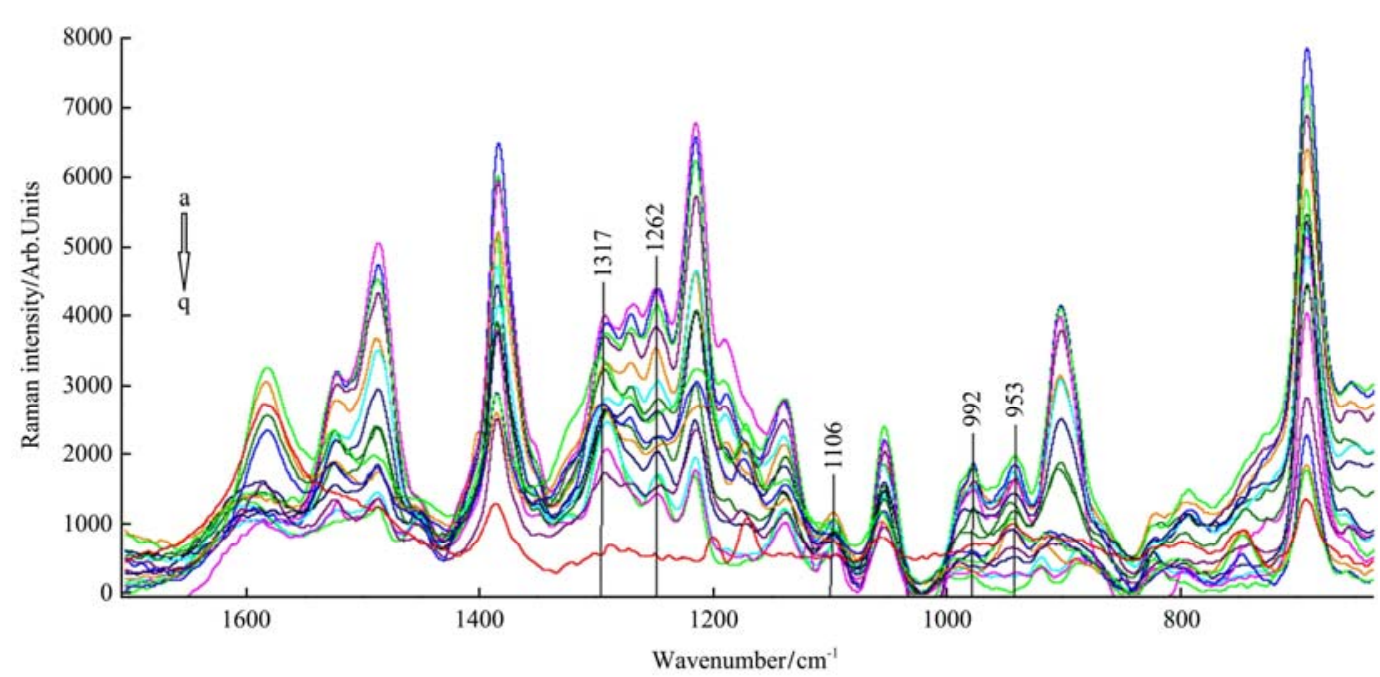

Figure 4 SERS spectra of different concentrations of histamine in Miichthys miiuy

(a-q: $400 \mathrm{mg} / \mathrm{kg}, 375 \mathrm{mg} / \mathrm{kg}, 350 \mathrm{mg} / \mathrm{kg}, 325 \mathrm{mg} / \mathrm{kg}, 300 \mathrm{mg} / \mathrm{kg}, 275 \mathrm{mg} / \mathrm{kg}, 250 \mathrm{mg} / \mathrm{kg}, 225 \mathrm{mg} / \mathrm{kg}, 200 \mathrm{mg} / \mathrm{kg}$,

$175 \mathrm{mg} / \mathrm{kg}, 150 \mathrm{mg} / \mathrm{kg}, 125 \mathrm{mg} / \mathrm{kg}, 100 \mathrm{mg} / \mathrm{kg}, 75 \mathrm{mg} / \mathrm{kg}, 50 \mathrm{mg} / \mathrm{kg}, 25 \mathrm{mg} / \mathrm{kg}, 5 \mathrm{mg} / \mathrm{kg}, 0 \mathrm{mg} / \mathrm{kg}$ ) 
Because the intensity was high at $1262 \mathrm{~cm}^{-1}$ and there were no peaks piled and impure peaks in the vicinity, the intensity of this peak was chosen to establish a quantitative model for histamine content determination in fresh fish. Figures $5 \mathrm{a}$ and $5 \mathrm{~b}$ showed a linear standard curve between the SERS characteristic peak intensity $\left(1262 \mathrm{~cm}^{-1}\right)$ and the concentration of histamine (5$400 \mathrm{mg} / \mathrm{kg}$ ). The linear equation was $y=7.3425 x-1.1358$, and the correlation coefficient $\left(R^{2}\right)$ was 0.9755 . These results demonstrated that the sample preparation protocol

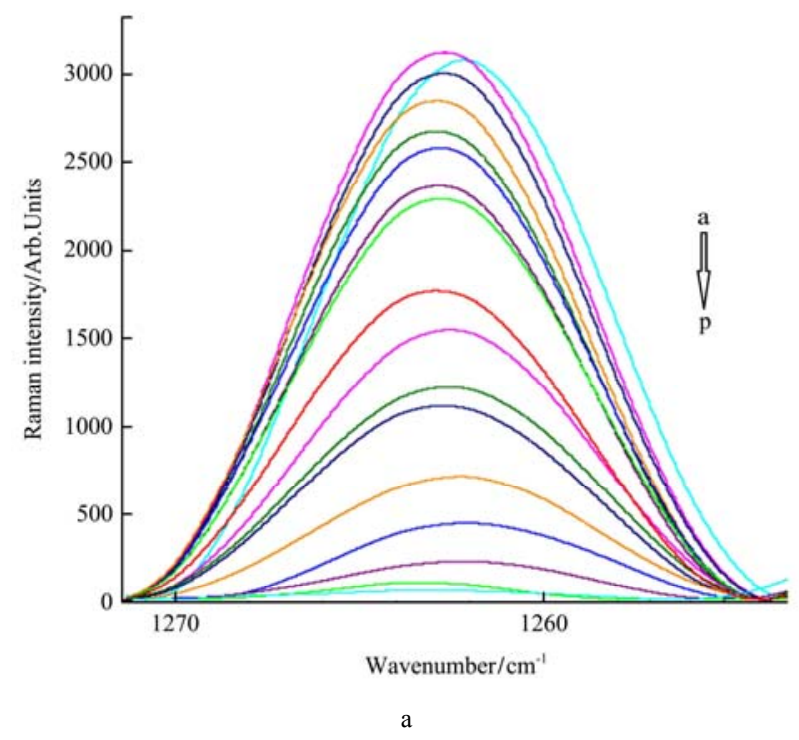

and SERS combined with DFT in this study could qualitatively and quantitatively analyze the histamine in fresh fish at the levels covering legislative limit in EU countries, US and China. The whole process was simple, which did not include extracting by n-hexane, degreasing, derivatization and other steps as compared to the Chinese national standard method (approximately $5 \mathrm{~h}$ ). Moreover, the time required for pre-processing was only one-fifteenth of that of the traditional method.

Figure 5 SERS spectra $\left(1262 \mathrm{~cm}^{-1}\right)$ of Miichthys miiuy spiked with different concentrations

(a-p: $400 \mathrm{mg} / \mathrm{kg}, 375 \mathrm{mg} / \mathrm{kg}, 350 \mathrm{mg} / \mathrm{kg}, 325 \mathrm{mg} / \mathrm{kg}, 300 \mathrm{mg} / \mathrm{kg}, 275 \mathrm{mg} / \mathrm{kg}, 250 \mathrm{mg} / \mathrm{kg}, 225 \mathrm{mg} / \mathrm{kg}, 200 \mathrm{mg} / \mathrm{kg}, 175 \mathrm{mg} / \mathrm{kg}$, $150 \mathrm{mg} / \mathrm{kg}, 125 \mathrm{mg} / \mathrm{kg}, 100 \mathrm{mg} / \mathrm{kg}, 75 \mathrm{mg} / \mathrm{kg}, 50 \mathrm{mg} / \mathrm{kg}, 25 \mathrm{mg} / \mathrm{kg}$ and $5 \mathrm{mg} / \mathrm{kg}$ ) of histamine (a) and its linear equation (b)

\section{Conclusions}

In this study, a simple sample pretreated protocol was developed to significantly shorten the sample preparation time as compared to the Chinese national standard method. Gold nanoparticles had a better effect on histamine molecules for the SERS spectra collection than silver nanoparticles. Five Raman characteristic peaks $\left(953 \mathrm{~cm}^{-1}, 992 \mathrm{~cm}^{-1}, 1106 \mathrm{~cm}^{-1}, 1262 \mathrm{~cm}^{-1}\right.$ and $\left.1317 \mathrm{~cm}^{-1}\right)$ obtained by SERS-DFT can be used as a qualitative and quantitative basis for the determination of histamine in fresh fish. The intensity of the characteristic peak of spectra at $1262 \mathrm{~cm}^{-1}$ was linearly correlated with the histamine at the concentration of $5-400 \mathrm{mg} / \mathrm{kg}$ with $R^{2}=0.9755$, implying that the SERS-DFT approach could rapidly and reliably detect histamine at levels from $5 \mathrm{mg} / \mathrm{kg}$ to $400 \mathrm{mg} / \mathrm{kg}$ in fresh fish.

\section{Acknowledgments}

This study was financially supported by " 863 " National High-Tech Research and Development Plan (Project No: 2013AA102301) and Zhejiang Provincial Science \& Technology Innovation team Project.

\section{[References]}

[1] Bulushi I A, Poole S P, Deeth H C, Dykes G A. Biogenic amines in fish: roles in intoxication, spoilage, and nitrosamine formation-a review. Critical Reviews in Food Science and Nutrition, 2009; 49(4): 369-377.

[2] Taylor S L, Eitenmiller R R. Histamine food poisoning: toxicology and clinical aspects. CRC Critical Reviews in Toxicology, 1986; 17(2): 91-128.

[3] Shalaby A R. Significance of biogenic amines to food safety and human health. Food Research International, 1996; 29(7): 675-690.

[4] Akdis C A, Simons F E R. Histamine receptors are hot in 
immunopharmacology. European Journal of Pharmacology; 2006; 533(1): 69-76.

[5] GB 2733-2015, Fresh and Frozen Animal Aquatic Products. China's National Health and Family Planning Commission, Beijing, 2015. (in Chinese)

[6] Silva C C G, Ponte D J B, Dapkevicius M L N E. Storage temperature effect on histamine formation in big eye tuna and skipjack. Journal of Food Science, 1998; 63(4): 644-647.

[7] Becker K, Southwick K, Reardon J, Berg R, MacCormack J N. Histamine poisoning associated with eating tuna burgers. Journal of the American Medical Association, 2001; 285(10): $1327-1330$

[8] Tahmouzi S, Khaksar R, Ghasemlou M. Development and validation of an HPLC-FLD method for rapid determination of histamine in skipjack tuna fish (Katsuwonus pelamis). Food Chemistry, 2011; 126(2): 756-761.

[9] Cinquina A L, Cali A, Longo F, Santis L D, Severoni A, Abballe F. Determination of biogenic amines in fish tissues by ion-exchange chromatography with conductivity detection. Journal of Chromatography A, 2004; 1032(1-2): 73-77.

[10] Onal A. A review: current analytical methods for the determination of biogenic amines in foods. Food Chemistry, 2007; 103(4): 1475-1486.

[11] Pessatti T L P, Fontana J D, Pessatti M L. Spectrophotometric determination of histamine in fisheries using an enzyme immunoassay method. Public Health Microbiology: Methods and Protocols, 2004; pp.311-316.

[12] Mueller C, David L, Chis V, Pinzaru S C. Detection of thiabendazole applied on citrus fruits and bananas using surface enhanced Raman scattering. Food Chemistry, 2014; 145: 814-820.

[13] Xu H X, Aizpurua J, Käll M, Apell P. Electromagnetic contributions to single-molecule sensitivity in surface-enhanced Raman scattering. Physical Review E, 2000; 62(3): 4318-4324.

[14] Camden J P, Dieringer J A, Wang Y, Masiello D J, Marks L D, Schatz G C, et al. Probing the structure of singlemolecule surface-enhanced Raman scattering hot spots. Journal of the American Chemical Society, 2008; 130(38): 12616-12617.

[15] Huang S G, Hu J P, Guo P, Liu M H, Wu R M. Rapid detection of chlorpyriphos residue in rice by surface-enhanced Raman scattering. Analytical Methods, 2015; 7(10): 4334-4339.

[16] Zheng J K, He L L. Surface-enhanced Raman spectroscopy for the chemical analysis of food. Comprehensive Reviews in Food Science and Food Safety, 2014; 13(3): 317-328.

[17] Li D W, Zhai W L, Li Y T, Long Y T. Recent progress in surface enhanced Raman spectroscopy for the detection of environmental pollutants. Microchimica Acta, 2014; 181(1-2): 23-43.

[18] Gao F, Grant E, Lu X N. Determination of histamine in canned tuna by molecularly imprinted polymers-surface enhanced Raman spectroscopy. Analytica Chimica Acta, 2015; 901: 68-75

[19] Xie Z J, Wang Y, Chen Y S, Xu X M, Jin Z Y, Ding Y L, et al. Tuneable surface enhanced Raman spectroscopy hyphenated to chemically derivatized thin-layer chromatography plates for screening histamine in fish. Food Chemistry, 2017; 230: 547-552.

[20] Zhang X Y, Young M A, Lyandres O, Van Duyne R P. Rapid detection of an anthrax biomarker by surface-enhanced Raman spectroscopy. Journal of the American Chemical Society, 2005; 127(12): 4484-4489.

[21] GB/T 5009. 208-2008. Determination of Biogenic Amine in Foods. China's National Health and Family Planning Commission, Beijing, 2008. (in Chinese)

[22] Guo H. Biogenic amines profile and characteristic amines analysis at different storage temperature in marine fishes. Master thesis, Zhejiang University, 2015. (in Chinese)

[23] Kim K B, Han J-H, Choi H, Kim H C, Chung T D. Dynamic preconcentration of gold nanoparticles for surface-enhanced Raman scattering in a microfluidic system. Small, 2012; 8(3): 378-383.

[24] Buyukgoz G G, Bozkurt A G, Akgul N B, Tamer U, Boyaci I H. Spectroscopic detection of aspartame in soft drinks by surface-enhanced Raman spectroscopy. European Food Research and Technology, 2015; 240(3): 567-575.

[25] Torreggiani A, Tamba M, Bonora S, Fini G. Raman and IR study on copper binding of histamine. Biopolymers, 2003; 72(4): 290-298. 